\title{
Dating of sediments in the Biscay bay: Implication for pollution chronology
}

\author{
S. Schmidt ${ }^{1,2}$, J. Tronczynski ${ }^{3}$, N. Guiot ${ }^{3}$ and I. Lefevre ${ }^{2}$ \\ ${ }^{1}$ UMR 5805 EPOC, Département de Géologie et d'Océanographie, 33405 Talence, France \\ ${ }^{2}$ UMR1572 LSCE, 91198 Gif-sur-Yvette Cedex, France \\ ${ }^{3}$ Ifremer, Direction de l'Environnement et de l'Aménagement du Littoral, Département des \\ Polluants Chimiques, BP. 21105, 44311 Nantes, France
}

\begin{abstract}
Important historical informations on the temporal changes of anthropogenic pollution in marine environment can be assessed using sediment analysis. Dating is a crucial prerequisite to reconstruct pollution events, to calculate fluxes, and thus to allow comparison between different sites. This work presents estimates of accumulation rates of sediments in the Bay of Biscay. Fives cores were collected during RIKEAU 2002 cruise on board o/v Thalia in order to study temporal changes in PAH and organohalogens compounds content of sediment. We compare chronostratigraphic estimates on cores derived from the natural radionuclide ${ }^{210} \mathrm{~Pb}$ in excess with estimates from the known times of introduction of the artificial radionuclide ${ }^{137} \mathrm{Cs}$ to the environment. ${ }^{210} \mathrm{~Pb},{ }^{226} \mathrm{Ra}$ and ${ }^{137} \mathrm{Cs}$ were measured directly by non-destructive gamma spectrometry using a well type $\gamma$-detector. Total ${ }^{210} \mathrm{~Pb}$ and ${ }^{226} \mathrm{Ra}$ activities vary from 30 to $150 \mathrm{mBq} \mathrm{g}^{-1}$, and 20 to $36 \mathrm{mBq} \mathrm{g}^{-1}$ respectively; ${ }^{137} \mathrm{Cs}$ presents lower levels $\left(<5 \mathrm{mBq} \mathrm{g}^{-1}\right)$. Profiles of ${ }^{210} \mathrm{~Pb}_{\mathrm{xs}}$ in three cores present a well mixed layer, from $2-3$ to $10 \mathrm{~cm}$, in the uppermost sediments, followed by an exponential decrease of activities, suitable for the determination of sedimentation rates. Under constant flux and sedimentation rate assumptions, vertical accretion rates derived from ${ }^{210} \mathrm{~Pb}_{\mathrm{xs}}$ present a large range from nearly $0.1 \mathrm{~cm} \mathrm{yr}^{-1}$ up to almost $0.3 \mathrm{~cm} \mathrm{yr}^{-1}$. Differences are mainly due to relative position of studied cores regarding the muddy patch. Although the moderate level of ${ }^{137} \mathrm{Cs}$ limits the accuracy of this dating method, profiles of ${ }^{137} \mathrm{Cs}$ with depth strengthen mean rates derived from ${ }^{210} \mathrm{~Pb}_{\mathrm{xs}}$ data. The implication of this dating on pollutant inputs in sediments of the Bay of Biscay is briefly discussed.
\end{abstract}

\section{INTRODUCTION}

Chronologies of contaminant input are dependent on the ability to establish the depositional history of the sediment [1]. In such a context, determination of sediment accumulation rates is an important aspect of biogeochemical and environmental investigations in coastal sediments. Sediment accumulation rates have been widely determined in silty and muddy nearshore environments using radiometric and chemical methods, involving the identification of one or more elements whose inputs are known and which, once deposited, are immobile in the sediment column [2]. During the last two decades, radionuclides such as ${ }^{210} \mathrm{~Pb}$ or ${ }^{137} \mathrm{Cs}$ have often been used as chronometers for estimating accumulation and mixing rates in marine and lake sediments ([3]; [4]; [5]). The distribution of a particle-reactive radionuclide in a sediment column can result from either sediment accumulation alone or from bioturbation plus sediment accumulation [6]. These effects can to some extent be resolved by using natural and artificial radionuclides with different half-lives and inputs: ${ }^{137} \mathrm{Cs}(30.2 \mathrm{y}$, weapon tests and Chernobyl event) and ${ }^{210} \mathrm{~Pb}\left(22.3 \mathrm{y}\right.$, with steady input). The ${ }^{210} \mathrm{~Pb}$ method gives an average accumulation rate for the past 100 years (i.e. five times its half-life), while ${ }^{137} \mathrm{Cs}$ is applicable for the last 45 years. 
In this paper we report depth profiles of ${ }^{210} \mathrm{~Pb},{ }^{226} \mathrm{Ra}$ and ${ }^{137} \mathrm{Cs}$ established in five cores recovered at different locations in the Bay of Biscay, North-East Atlantic. Radionuclide profiles are interpreted in order to determine sediment accumulation at each site. These rates are then used to date sediment layers in order to allow further reconstruction of the history of pollutant inputs in these sediments.

Table 1. Core list and map of the bay of Biscay and location of the five sampling sites.

\begin{tabular}{ccccccc}
\hline Label & Position & & $\begin{array}{c}\text { Depth } \\
(\mathrm{m})\end{array}$ \\
\hline RiK01 & $46^{\circ} 05,21 \mathrm{~N}$ & $1^{\circ} 18,28 \mathrm{~W}$ & 36 \\
RiK02 & $45^{\circ} 42,04 \mathrm{~N}$ & $1^{\circ} 42,28 \mathrm{~W}$ & 54 \\
RiK03 & $47^{\circ} 02,539 \mathrm{~N}$ & $2^{\circ} 06,453 \mathrm{~W}$ & 16 & \\
RiK18 & $47^{\circ} 35,819 \mathrm{~N}$ & $4^{\circ} 00,679 \mathrm{~W}$ & 87 & \\
RiK20 & $47^{\circ} 20,883 \mathrm{~N}$ & $2^{\circ} 41,064 \mathrm{~W}$ & 27 & Figure 1. Site location
\end{tabular}

\section{SAMPLING AND METHODS}

The five studied cores were recovered in shallow sediments of the bay of Biscay (Table 1) during RIKEAU cruise (May, 2002) on board $\mathrm{r} / \mathrm{v}$ Thalia. The main objective of this cruise was to investigate temporal changes in PAH and organohalogens compounds (PCB, PBDE and PCDD/Fs) content of sediment. About 4-g aliquots of dry sediment were measured directly by non-destructive gamma spectrometry to determine activities of the following radionuclides: ${ }^{137} \mathrm{Cs}(30 \mathrm{y}),{ }^{210} \mathrm{~Pb}(22.3 \mathrm{y})$ and ${ }^{226} \mathrm{Ra}(1600 \mathrm{y})$. Measurements were carried out using a low-background well-type $\gamma$-detector (EURISYS Mesures, germanium crystal volume of $110 \mathrm{~cm}^{3}$ ) [7]. The standards used to calibrate the $\gamma$-detector are mixtures of marine sediment with US NBS U and Th standards at $1000 \mathrm{ppm}$ for U and Th-decay series, and IAEA gamma standard IAEA-375 for ${ }^{137} \mathrm{Cs}$. In practice, ${ }^{210} \mathrm{~Pb}$ and ${ }^{137} \mathrm{Cs}$ were measured directly through their gamma emissions at 46.5 and $661.6 \mathrm{keV}$ respectively. On the other hand ${ }^{226} \mathrm{Ra}$ was determined using selected gamma rays emitted by its short-lived daughters: ${ }^{214} \mathrm{~Pb}(295.2$ and $352.0 \mathrm{keV})$ and ${ }^{214} \mathrm{Bi}(609.3 \mathrm{keV}) .{ }^{210} \mathrm{~Pb}$ in excess of the steady production from ${ }^{226} \mathrm{Ra},{ }^{210} \mathrm{~Pb}_{\mathrm{xs}}$, was calculated as the difference between measured ${ }^{210} \mathrm{~Pb}$ and ${ }^{226} \mathrm{Ra}$. Activities are expressed in $\mathrm{mBq} \mathrm{g}{ }^{-1}$. Figure 2 shows profiles of ${ }^{210} \mathrm{~Pb}_{\mathrm{xs}}$ and ${ }^{137} \mathrm{Cs}$ with depth for the five studied cores. In the following section, results are presented per core.

\section{RESULTS}

\subsection{Core RiK01}

Core RiK01 exhibits profiles of ${ }^{210} \mathrm{~Pb}_{\mathrm{xs}}$ and ${ }^{137} \mathrm{Cs}$ rather homogeneous throughout the whole core, (38 cm in length) (Figure 2). At about $25 \mathrm{~cm}$ in depth, both radionuclides present punctually significantly lower values. But below this layer, values are again at same levels as observed in the top of the core. Rather a chronological signal, this may reflect a bed representing a distinct sedimentological event. The absence of lithologic informations precludes further interpretation. Even so radionuclide profiles reveal an important mixing of sediment. This may be in relation with the position of core RiK01 in the bay of Pertuis d'Antioche, a highly dynamic area. Such a feature does not allow to estimate sedimentation rates on core RiK01 with the considered tracers. 


\subsection{Core RiK02}

Profiles of ${ }^{210} \mathrm{~Pb}_{\mathrm{xs}}$ and ${ }^{137} \mathrm{Cs}$ in core RiK02 appear completely different from the previous ones. ${ }^{210} \mathrm{~Pb}_{\mathrm{xs}}$ activities show a well defined mixed layer of $7 \mathrm{~cm}$ thickness, followed by an exponential decrease to rather negligible values below $30 \mathrm{~cm}$ depth. ${ }^{137} \mathrm{Cs}$ profile is remarkable too with a typical shape. Below the upper mixed layer, equivalent to that observed for ${ }^{210} \mathrm{~Pb}_{\mathrm{xs}}$, ${ }^{137} \mathrm{Cs}$ presents a subsurface peak at about 13-14 cm depth, which is likely to correspond to an introduction event of ${ }^{137}$ Cs. Thereafter activities of this artificial radionuclide decrease smoothly to disappear after $25 \mathrm{~cm}$. This core is appropriate for dating.

\subsection{Core RiK03}

As for RiK01, profiles of ${ }^{210} \mathrm{~Pb}$ in excess and ${ }^{137} \mathrm{Cs}$ are nearly constant over the $25 \mathrm{~cm}$ of core RiK03 (Figure 2). Such a mixed layer highlights important mixing, that could be related to the position of the core in the bay of Bourgneuf. Indeed this bay, well protected, is characterized by the presence of numerous worms, which create an important bioturbation. This core is not appropriate for dating.
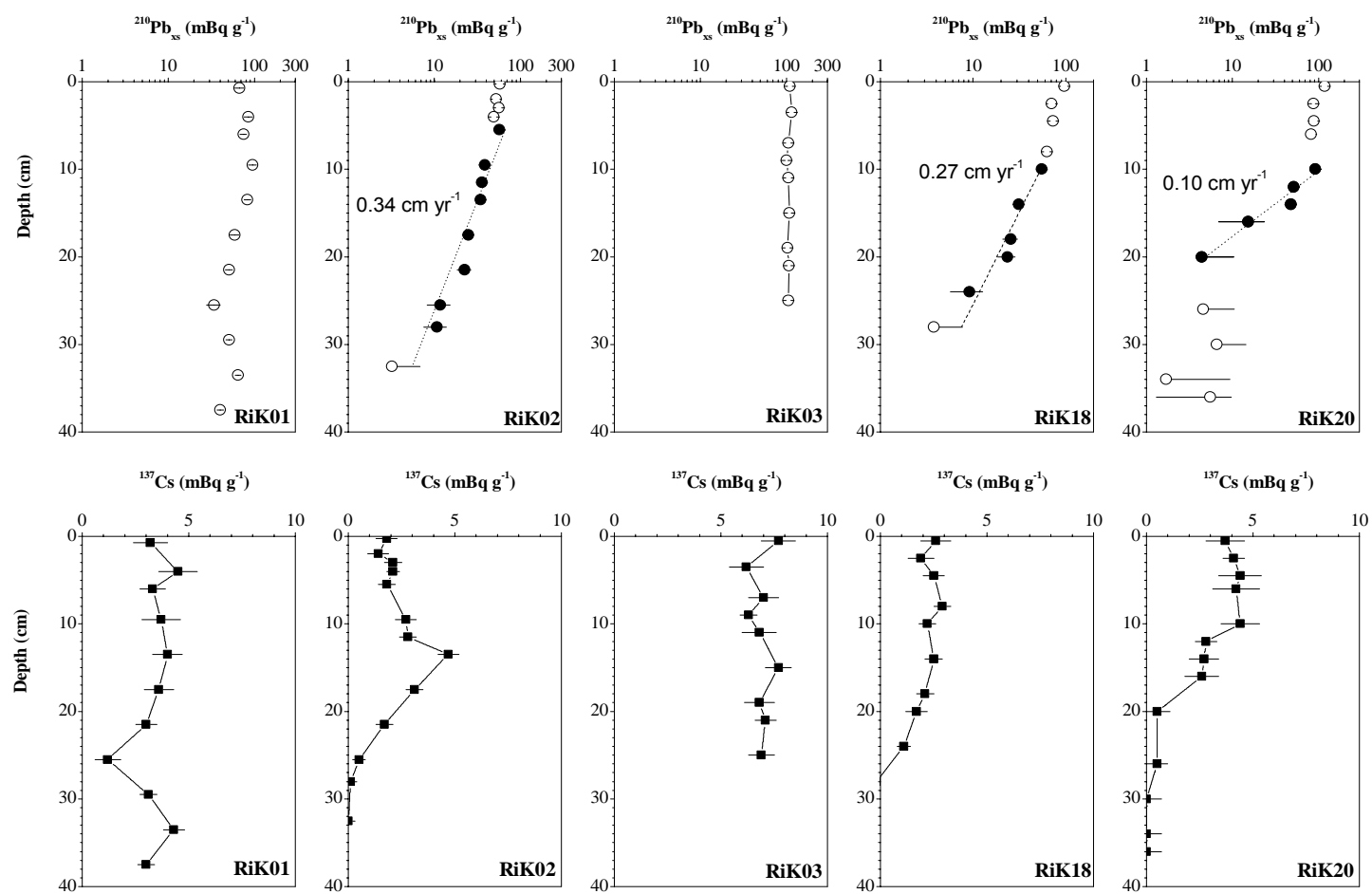

Figure 2. Excess ${ }^{210} \mathrm{~Pb}$ and ${ }^{137} \mathrm{Cs}$ versus depth in sediment cores (see map in Figure 1 for location). Dark points on ${ }^{210} \mathrm{~Pb}_{\mathrm{xs}}$ profiles point out data retained for sedimentation rate determination.

\subsection{Core RiK18}

In core RiK18, ${ }^{210} \mathrm{~Pb}_{\mathrm{xs}}$ activities show the expected exponential decrease from high surface activities to close to secular equilibrium at depth deeper than $30 \mathrm{~cm}$ (Fig. 2). However, it presents a thick mixed layer, about $10 \mathrm{~cm}$, in the upper part of core. ${ }^{137} \mathrm{Cs}$ profile is less expressed than previously observed for Rik02. It could be a smoothing effect of more intense mixing. ${ }^{137} \mathrm{Cs}$ activities are significant in the upper $20 \mathrm{~cm}$, and then decrease rapidly to negligible levels below $25 \mathrm{~cm}$. 


\subsection{Core RiK20}

${ }^{210} \mathrm{~Pb}_{\mathrm{xs}}$ profile in core RiK2 is very classical with a mixed layer well marked within the upper $11 \mathrm{~cm}$ (Fig. 2). Thereafter ${ }^{210} \mathrm{~Pb}_{\mathrm{xs}}$ decreases rapidly to reach negligible values beyond $20 \mathrm{~cm}$. Profile of ${ }^{137} \mathrm{Cs}$ presents similar characteristics with an extended mixed layer, followed by a disappearance of this element around $20 \mathrm{~cm}$ depth. Both radionuclides show a reduced penetration in depth, limited to the upper $20 \mathrm{~cm}$, when compared to RiK02 and RiK18 (about $30 \mathrm{~cm}$ ).

\section{DISCUSSION}

\subsection{Sedimentation rate determination derived from ${ }^{210} \mathrm{~Pb}$}

The ${ }^{210} \mathrm{~Pb}$ method is based on the measurement of the excess or unsupported activity ${ }^{210} \mathrm{~Pb}$, which is incorporated rapidly into the sediment from atmospheric fallout ([1]; and references herein]). Once incorporated into the sediment, unsupported ${ }^{210} \mathrm{~Pb}$ decays with depth, equivalent to time, in the sediment column according to its known half-live. In applying this principle, it is assumed that the specific activity of newly deposited particles at a given site is constant with time. Therefore, sediment accumulation rate can be derived from ${ }^{210} \mathrm{~Pb}$, based on two assumptions: constant flux and constant sediment accumulation rate (CF:CS method) ([3]). Then the decrease of ${ }^{210} \mathrm{~Pb}_{\mathrm{xs}}$ activities with depth is described by the following relation:

$$
\left[{ }^{210} \mathrm{~Pb}_{\mathrm{xs}}\right]_{\mathrm{z}}=\left[{ }^{210} \mathrm{~Pb}_{\mathrm{xs}}\right]_{0} \exp [-\lambda \mathrm{z} / \mathrm{S}]
$$

where $\left[{ }^{210} \mathrm{~Pb}_{\mathrm{xs}}\right]_{0}, \mathrm{z}$ are the activities of excess ${ }^{210} \mathrm{~Pb}$ at surface, or base of the mixed layer, and depth $\mathrm{z}, \boldsymbol{\lambda}$ is the decay constant of the nuclide, and $\mathrm{S}$ is the sediment accumulation rate.

For cores RiK1 and Rik3, strong mixing, as revealed by a thick mixed layer extended to the whole depth of cores, precluded such calculations. Therefore, we applied this method to the profiles of ${ }^{210} \mathrm{~Pb}_{\mathrm{xs}}$ of this work presenting a significant decrease of activities with depth in sediment (RiK02, RiK18, RiK20, Figure 2). Sedimentation rates derived from ${ }^{210} \mathrm{~Pb}_{\mathrm{xs}}$ profiles on cores RiK02, RiK18 and RiK20 are respectively $0.34,0.27$ and $0.10 \mathrm{~cm}$ per year.

\section{$4.2{ }^{137}$ Cs test of sedimentation rates}

One can be more confident that the sedimentary record is of realistic value if the inferred sediment accumulation rate could be confirmed by an independent time marker such as ${ }^{137} \mathrm{Cs}$. In contrast to ${ }^{210} \mathrm{~Pb},{ }^{137} \mathrm{Cs}$ does not occur naturally: it is a product of nuclear weapons testings and power plant accidents. The use of ${ }^{137} \mathrm{Cs}$ for dating recent deposition is based on several hypotheses described in [8]. The first occurrence in the environment resulted from fallout of atmospheric nuclear weapons tests in the early 1950s, with a maximum input in 1963. More recently, in northern Europe, the Chernobyl accident of 26 April 1986 introduced a new, patchy, ${ }^{137} \mathrm{Cs}$ input ([9]; [10]). As a consequence of these distinct input events, it is possible to date a core when peaks in ${ }^{137} \mathrm{Cs}$ activity, recording the 1963 fallout maximum and/or the Chernobyl event, are found [11]. Another constraint is to consider the maximum depth of ${ }^{137} \mathrm{Cs}$ penetration $(\mathrm{H})$, directly related to sediment accumulation as:

$$
\mathrm{H}=\mathrm{L}+\mathrm{St}
$$

where $\mathrm{L}$ the thickness of the mixed layer, $\mathrm{S}$ the sedimentation rate and $\mathrm{t}$ is the elapsed time since ${ }^{137} \mathrm{Cs}$ reached the seabed. Where mixing occurs at the surface, as for the present cores, the predicted depth of penetration is equal to St $+\mathrm{L}$ [12]. The predicted penetration depth of ${ }^{137} \mathrm{Cs}$ was calculated considering that the first input into these sediments began in 1950 .

For core RiK02, the sedimentation rate inferred from ${ }^{210} \mathrm{~Pb}_{\mathrm{xs}}\left({ }^{210} \mathrm{~Pb}_{\mathrm{xs}} \mathrm{S}, 0.34 \mathrm{~cm} \mathrm{yr}^{-1}\right)$ and the thickness of the mixed layer $(7 \mathrm{~cm})$ put Chernobyl peak at $12.4 \mathrm{~cm}$ and the maximum penetration depth of ${ }^{137} \mathrm{Cs}$ at about $25 \mathrm{~cm}$. These estimates agree well very with ${ }^{137} \mathrm{Cs}$ profile (Figure 2) and accordingly validate ${ }^{210} \mathrm{~Pb}_{\mathrm{xs}}-\mathrm{S}$. Same calculations were done for cores RiK18 and RiK20 and strengthen in the same way sedimentation rates derived from ${ }^{210} \mathrm{~Pb}_{\mathrm{xs}}$. 


\subsection{Sedimentation feature of the Biscay bay}

Surprisingly there are only few works reporting sedimentation investigations of the shelf of the Biscay Bay ([5], [13] [14]). The French Atlantic shelf presents nearshore mud belts, mainly extended between 30 and 75 m water depth: the Gironde mud fields and "La Grande Vasière" [15] (Figure 3).

Core RiK02 is located on the north-western border of the Gironde shelf mud fields. This mud patch is influenced by the terrigeneous dispersal system from Gironde outlet [15]. Sedimentation rates are of about $0.5 \mathrm{~cm} \mathrm{yr}^{-1}$ in the depocenter of the main mud field to $0.1-0.2 \mathrm{~cm} \mathrm{yr}^{-1}$ in the outer zone where the supply is reduced [14]. Taking into account its location, the value of $0.34 \mathrm{~cm} \mathrm{yr}^{-1}$ measured in core RiK02 is coherent with this trend.

Core RiK18 was recovered northward "La Grande Vasière” (Figure 3). Lesueur et al. [14] pointed out the difficulties to obtain good records in the southern area of "La Grande Vasière" due to episodic sediment removals by long-period swells and bioturbation. RiK18 presents an important surface layer in radionuclide profiles, which could be ascribed to such bioturbation effects; but deeper in the core the rapid decrease in activities is suitable for accumulation rate determination. The sedimentation rate derived from ${ }^{210} \mathrm{~Pb}_{\mathrm{xs}}, 0.27 \mathrm{~cm} \mathrm{yr}^{-1}$, is strengthened by ${ }^{137} \mathrm{Cs}$ data. This value is in the range of estimates for nearshore mud belts of the Atlantic shelf of the Biscay Bay (Figure 3).

Unfortunately, there is no published estimation of sedimentation rate near core RiK20. Nevertheless, it is noticeable that ${ }^{210} \mathrm{~Pb}_{\mathrm{xs}}$ derived sedimentation rate of core RiK20 is in the range reported by [14] for south proximal area at depth lower to $40 \mathrm{~m}$.

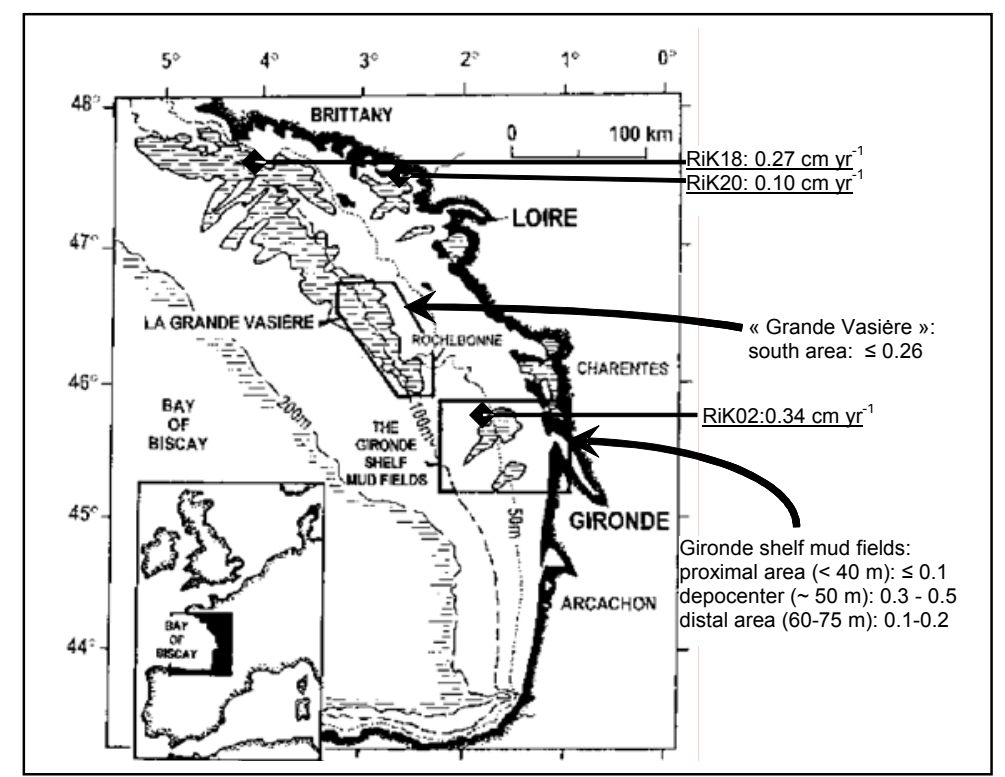

Figure 3. Mud belts of the French shelf of the Bay of Biscay. Adapted from Allen [15] and Lesueur et al. [14]. Range values, in $\mathrm{cm} \mathrm{yr}^{-1}$, for the Gironde shelf mud fields and "La Grande Vasière" are from Lesueur et al. [14].

\subsection{Implication for the reconstruction of pollutant history}

Calculating sedimentation rates in marine sediments using radionuclides is an efficient and widely used method. But a more tricking issue is to date core horizons. When knowing sedimentation, one needs a stratigraphic mark to anchor the time scale. In the present case, it is provided by ${ }^{137} \mathrm{Cs}$ as the timing of introduction of this artificial radionuclides in the environment is well established. Assuming constant sedimentation rates over the covered period and ${ }^{137} \mathrm{Cs}$ as a time marker, it is possible to reconstruct the chronology of cores. Temporal scales collected by cores Rik02 and RiK18 are 
restricted to the last century: deepest horizons (around 35-36 cm) correspond to year 1920 for Rik02 and year 1906 for RiK18. On the other hand, due to lowest sedimentation rate, the deepest layers of core Rik20 correspond early XVII ${ }^{\mathrm{e}}$. This example illustrates how temporal range covered by a core of about $40 \mathrm{~cm}$ could be extremely variable depending of sedimentation rate and intensity of mixing.

An important goal of Rikeau cruise was to investigate the impact on the Bay of Biscay of the Erika sinking, which occurred the December, 12, 1999. A major result of this preliminary study using radionuclides is to reveal important mixed layers $(>8 \mathrm{~cm})$ whatever the location of studied cores throughout the French shelf of the Bay of Biscay. Such a mixing may have an important impact on the penetration of pollutants within the sedimentary column. In such investigations, core Rik20, by covering an important time range, is of major interest, as the base of the core may allow to measure pre-industrial concentrations.

\section{CONCLUSION}

A series of sediment cores have been collected in shallow sediments of the Biscay bay, North-East Atlantics. A detailed investigation of ${ }^{210} \mathrm{~Pb}$ in excess and ${ }^{137} \mathrm{Cs}$ allowed the characterisation of long-term sediment accumulation patterns on these cores. Sediment accumulation rates, derived from radionuclide profiles, are between 0.10 to $0.34 \mathrm{~cm} \mathrm{yr}^{-1}$, depending of core location, and are consistent with previous works in this area. This calculation was not possible for two cores, collected in bays; both exhibit deep mixed layers which overlap the length of studied cores $(35-40 \mathrm{~cm})$. One possibility to estimate sedimentation rates at these sites could be to collect longer cores $(>1 \mathrm{~m})$.

This example clearly illustrates that the ${ }^{137} \mathrm{Cs}$ dating technique, in combination with ${ }^{210} \mathrm{~Pb}_{\mathrm{xs}}$ measurements, is an indirect but efficient method of dating core horizons in modern sedimentary environments.

\section{Acknowledgments}

The captain and crew of r/v Thalia are thanked for logistic support. This work was partly supported by the Ifremer (contract 03/5210 096), the CNRS and the CEA. This is UMR5805 EPOC-DGO ${ }^{\circ}{ }^{\circ} x x x$, UMR 1572 and LSCE $n^{\circ} \mathrm{xxxx}$, contributions.

\section{References}

[1] Appleby P.G. and Olfield F., Application of lead-210 to sedimentation studies, in Uranium-series Disequilibrium: Applications to Earth, Marine, and Environmental Sciences (Clarendon Press, Oxford, 1992) pp. 731-778.

[2] Cundy A.B. and Croudace I.W., Mar. Chem. 51 (1995) 115-132.

[3] Krishnaswamy S., Lal D., Martin, J.-M. and Meybeck M., Earth Planet. Sci. Lett. 11 (1971) 407-414.

[4] Robbins J. and Edgington D.N., Geochim. Cosmochim. Acta 39 (1975) 285-304.

[5] Jouanneau J.M., Weber O., Latouche C., Vernet J.P. and Dominik J., Cont. Shelf Res. 9 (1989) 325-342.

[6] Robbins J.A., Edgington D.N. and Kemp A.L.W., Quaternary Res. 10 (1978) 256-278.

[7] Schmidt S., van Weering T.E. and de Stigter H.C., Mar. Geol. 173 (2001) 55-67.

[8] Ritchie J.C., McHenry J.R. and Gill A.C., Limnol. Oceanogr, 18 (1973) 254-263.

[9] Dominik J., Burrus D. and Vernet J.P., Earth Planet. Sci. Lett., 84 (1987) 165-180.

[10] Callaway J.C., DeLaune R.D. and Patrick Jr. W.H., Limnol. Oceanogr. 41 (1996) 444-450.

[11] Schmidt S., Herman P.M.J. and Reyss J.-L., Radioprotection, 37 (2002) 789-794.

[12] Nittrouer C.A., DeMaster D.J., McKee B.A., Cutshall N.H. and Larsen I.L., Mar. Geol. 54 (1984) 201-221.

[13] Gouleau D., Jouanneau J.M., Weber O. and Sauriau P.G., Cont. Shelf Res. 20 (2000) 1513-1530.

[14] Lesueur P., Jouanneau J.-M., Boust D., Tastet J.-P. and Weber O., Cont. Shelf Res. 21 (2001) 1383-1401.

[15] Allen G.P. and Castaing P., Bulletin Institut de Géologie du bassin d'Aquitaine (Bordeaux), 21 (1977) 255-261. 